\title{
Prevalence, correlates and in-hospital outcomes of kidney dysfunction in hospitalized patients with heart failure in Buea-Cameroon
}

\author{
Ahmadou Musa Jingi ${ }^{1}$, Clovis Nkoke ${ }^{2,3 *}$, Jean Jacques Noubiap ${ }^{4}$, Denis Teuwafeu ${ }^{2,5}$, Alex T. Mambap ${ }^{1}$, \\ Cyrille Nkouonlack ${ }^{2,5}$, Ronald Gobina ${ }^{2}$, Debimeh Njume ${ }^{6}$, Anastase Dzudie ${ }^{3,6}$ and Gloria Ashuntantang ${ }^{1}$
}

\begin{abstract}
Background: Kidney dysfunction is common in patients with heart failure (HF) and has been associated with poor outcomes. This study aimed to determine the prevalence, correlates, and prognosis of kidney dysfunction in patients with HF in Cameroon, an understudied population.

Methods: We conducted a cross-sectional study in consecutive patients hospitalized with HF between June 2016 and November 2017 in the Buea Regional Hospital, Cameroon. Kidney dysfunction was defined as an estimated glomerular filtration rate $<60 \mathrm{ml} / \mathrm{min} / 1.73 \mathrm{~m}^{2}$. Prognostic outcomes included death and prolonged hospital stay (> 7 days). We also performed a sensitivity analysis excluding racial considerations.
\end{abstract}

Results: Seventy four patients ( $86.1 \%$ of those eligible) were included. Their median age was 60 (interquartile range: $44-72)$ years and $46.0 \%(n=34)$ were males. Half of patients $(n=37)$ had kidney dysfunction. Correlates of kidney dysfunction included previous diagnosis of HF (adjusted odds ratio [aOR]4.3, 95\% Cl: 1.1-17.5) and left ventricular hypertrophy (aOR3.4, 95\% Cl: 1.1-9.9). Thirty-six (48.9\%) had prolonged hospital stay, and seven (9.5\%) patients died in hospital. Kidney dysfunction was not associated with in-hospital death (aOR 0.4, 95\% Cl: 0.1-2) nor prolonged hospital stay (aOR 2.04, 0.8-5.3). In sensitivity analysis (excluding racial consideration), factors associated with Kidney dysfunction in HF were; anemia (aOR: 3.0, 95\% Cl: 1.1-8.5), chronic heart failure (aOR: 4.7, 95\% Cl: 0.9-24.6), heart rate on admission < 90 bpm (aOR: 3.4, 95\% Cl: 1.1-9.1), left atrial dilation (aOR: 3.2, 95\% Cl: 1.04-10), and hypertensive heart disease (aOR: 3.1, 95\% Cl: 1.2-8.4). Kidney dysfunction in HF was associated with hospital stay > 7 days (OR: 2.6, 95\% Cl: $1-6.8)$.

Conclusion: Moderate-to-severe kidney dysfunction was seen in half of the patients hospitalized with HF in our setting, and this was associated with a previous diagnosis of HF and left ventricular hypertrophy. Kidney dysfunction might not be the main driver of poor HF outcomes in this population. In sensitivity analysis, this was associated with anemia, chronic heart failure, heart rate on admission less than $90 \mathrm{bpm}$, left atrial dilatation, and hypertensive heart disease. Kidney dysfunction was associated with hospital stay $>7$ days.

Keywords: Kidney dysfunction, Heart failure, Outcome, Mortality, Cameroon, Sub-Saharan Africa

*Correspondence: cnkoke@yahoo.com

2 Buea Regional Hospital, Buea, Cameroon

Full list of author information is available at the end of the article

\section{Introduction}

Heart failure and chronic kidney diseases (CKDs) are common conditions in sub-Saharan Africa (SSA), where they account for about 35\% of all deaths [1-3]. Heart failure and CKD share common risk factors such as 
hypertension, obesity, and diabetes that have high prevalence rates in the region [1, 4-7]. In Cameroon, about one in three adults is hypertensive $[8,9]$ and one in nine has diabetes [10]. The burden of HF in the community is not known in our setting. Heart failure accounts for about 5\% of hospital consultations and admissions in adults, and hypertensive heart disease is the predominant cause of HF [4-6].

The community prevalence of CKD ranged from 10 to $14 \%$ [11]. This varied between risk groups and can be as high as $52 \%$ in those with hypertension [11, 12]. Kidney dysfunction and heart failure frequently co-exist and interact in a complex bi-directional and interdependent manner known as a cardiorenal syndrome [13]. Moderate-to-severe kidney dysfunction (eGFR $<60 \mathrm{ml} /$ $\mathrm{min} / 1.73 \mathrm{~m}^{2}$ ) can be seen in more than $30 \%$ of patients with heart failure $[14,15]$ and has been associated with increased mortality $[15,16]$. There is a dearth of data on the burden of kidney dysfunction in patients with heart failure in Cameroon (SSA), especially in semi-urban settings. This study aimed to determine the prevalence, correlates, and prognosis (in-hospital death and prolonged hospital stay) of kidney dysfunction in patients with heart failure admitted in a semi-urban setting in Cameroon.

\section{Methods}

\section{Study design and setting}

We carried out a prospective cross-sectional study in patients hospitalized with HF between June 2016 and November 2017 in the Internal Medicine Unit of the Buea Regional Hospital in the South West region of Cameroon. This is a second-level hospital with a bed capacity of 111 and a catchment population of over 200,000 inhabitants. The hospital serves as a teaching hospital for the Faculty of Health Sciences of the University of Buea and is equipped and staffed with personnel who are trained to diagnose and treat heart and kidney diseases. At the time of the study, $\mathrm{CN}$ was the only cardiologist in the region and who made the diagnosis of HF in all the patients.

\section{Study population and sample size}

We included all consenting patients aged $\geq 18$ years who were hospitalized with HF, with kidney function assessed on admission. The patients were consecutively recruited into an HF registry.

\section{Data collection}

The methods involved in this study have been previously described [5]. The data were prospectively collected with a predefined questionnaire. This constituted the first HF registry in the region. We collected demographic data (age and sex), medical history (previous diagnosis of HF, hypertension, diabetes, atrial fibrillation, alcohol consumption, tobacco use). Each patient underwent a complete clinical evaluation for symptoms and signs of HF $(\mathrm{CN})$. We measured the blood pressure according to standard procedures and a blood sample was collected for biochemical analysis including serum creatinine, sodium, potassium, hemoglobin, and fasting blood glucose. Each patient underwent a 12-lead resting electrocardiogram and a comprehensive cardiac ultrasound by a cardiologist $(\mathrm{CN})$ using a SonoscapeS8 ultrasound machine (Sonoscape, China).

\section{Variables}

Moderate-to-severe kidney dysfunction was defined as an estimated glomerular filtration rate (eGFR) $<60 \mathrm{ml} /$ $\min / 1.73 \mathrm{~m}^{2}$ ), similar to that reported in the European Society of Cardiology guidelines on heart failure and based on the Kidney Disease Outcome Quality Initiative (KDOQI) guidelines [17, 18]. The eGFR (in $\mathrm{mL} / \mathrm{min} .1 .73 \mathrm{~m}^{2}$ ) was estimated using the simplified Modification of Diet in Renal Disease (MDRD) equation: $(186.3 \times($ serum creatinine $(\mathrm{mg} / \mathrm{dl}))-1.154 \times$ age$0.203 \times(0.742$ if female $) \times(1.212$ if black African $)$. Those with any kidney impairment was defined as an eGFR $<90 \mathrm{ml} / \mathrm{min} / 1.73 \mathrm{~m}^{2}$. The severity of kidney impairment was defined according to the Kidney Disease Outcome Quality Initiative (KDOQI) as mild (60 $\left.89 \mathrm{ml} / \mathrm{min} / 1.73 \mathrm{~m}^{2}\right)$, moderate $\left(30-59 \mathrm{ml} / \mathrm{min} / 1.73 \mathrm{~m}^{2}\right)$, severe $\left(15-29 \mathrm{ml} / \mathrm{min} / 1.73 \mathrm{~m}^{2}\right)$, and failure $(<15 \mathrm{ml} /$ $\left.\min / 1.73 \mathrm{~m}^{2}, 19\right]$. We considered hyper-filtration as an eGFR $>130 \mathrm{ml} / \mathrm{min} / 1.73 \mathrm{~m}^{2}$ [19]. Outcome variables were in-hospital death or prolonged hospital stay ( $>7$ days).

\section{Statistical analyses}

We analyzed the data using IBM SPSS version 26 (IBM Corp, Armonk, NY, USA). Continuous variables are presented as means with standard deviation (SD) or median with interquartile range (IQR), and discrete variables as frequencies and proportions with the corresponding 95\% confidence intervals ( $95 \% \mathrm{CI})$. We compared means with independent sample $\mathrm{T}$-test and proportions with Chi-squared or Fischer exact test where appropriate. We assessed for factors associated with an eGFR $<60 \mathrm{ml} /$ $\mathrm{min} / 1.73 \mathrm{~m}^{2}$ in patients with HF in bivariate analyses and then adjusted for age (with a 55 years cutoff). We then assessed the association between eGFR and outcome measures of death or prolonged hospitalization using multivariable regression analysis with adjustment for age (55years cutoff) and sex. We also conducted a sensitivity analysis with an eGFR $<60 \mathrm{ml} / \mathrm{min} / 1.73 \mathrm{~m}^{2}$ without considering the black race. There were no missing data for the relevant variables studied. A $p$-value $<0.05$ was 
considered statistically significant for observed differences or associations.

\section{Ethical considerations}

This study was approved by the administrative authority of the Buea Regional Hospital acting as the local ethics committee. All participants or their legal guardians provided written informed consent to be included in the heart failure registry. All the patients approached accepted to be included in the registry.

\section{Results}

General characteristics

During the study period, 86 consecutive patients were hospitalized with HF. Of these, 74(86.1\%) patients had serum creatinine data on admission and were therefore included. The clinical characteristics are shown in Table 1. Thirty-four patients $(46.0 \%)$ were males. Their age ranged from 22 to 100 years, with a median (IQR) of 60 (IQR: 44-72) years (Table 1). Hypertension was the most frequent cardiovascular risk factor, seen in 42 (56.8\%, [95\% CI: 44.7-68.2]) patients. Previous diagnosis of HF was reported by 13 (17.6\%, [95\%

Table 1 Clinical characteristics of the participants hospitalized with heart failure $(n=74)$ : overall and by categories of kidney function

\begin{tabular}{|c|c|c|c|c|}
\hline \multirow[t]{2}{*}{ Variable } & \multirow[t]{2}{*}{ Overall $(n=74)$} & \multicolumn{2}{|c|}{ eGFR $\left(\mathrm{ml} / \mathrm{min} / 1.73 \mathrm{~m}^{2}\right)$} & \multirow[t]{2}{*}{$p$-value } \\
\hline & & $<60(n=37)$ & $\geq 60(n=37)$ & \\
\hline Age (years), mean (SD) & $58.7(17.9)$ & $61.9(16.6)$ & $55.5(18.9)$ & 0.4 \\
\hline Male sex, $\mathrm{n}(\%)$ & $34(45.9)$ & $17(45.9)$ & $17(45.9)$ & $>0.9$ \\
\hline \multicolumn{5}{|l|}{ Medical History, n(\%) } \\
\hline Chronic Heart Failure & $13(17.6)$ & $10(27)$ & $3(8.1)$ & 0.03 \\
\hline Hypertension & $42(56.8)$ & $22(59.5)$ & $20(54.1)$ & 0.6 \\
\hline Diabetes & $11(14.9)$ & $5(13.5)$ & $6(16.2)$ & 0.7 \\
\hline Current smoking & $6(8.1)$ & $4(10.8)$ & $2(5.4)$ & 0.4 \\
\hline Atrial Fibrillation & $2(2.7)$ & $2(5.4)$ & $0(0)$ & 0.2 \\
\hline Chronic Kidney Disease & $5(6.8)$ & $5(13.5)$ & $0(0)$ & 0.02 \\
\hline Alcohol consumption & $9(12.2)$ & $5(13.5)$ & $4(10.8)$ & 0.7 \\
\hline \multicolumn{5}{|l|}{ Symptoms, n (\%) } \\
\hline \multicolumn{5}{|l|}{ NYHA Class } \\
\hline$\|$ & $5(6.8)$ & $1(2.7)$ & $4(10.8)$ & 0.2 \\
\hline III & $38(51.4)$ & $23(62.2)$ & $15(40.5)$ & \\
\hline IV & $31(41.9)$ & $13(35.1)$ & $18(48.6)$ & \\
\hline Fatigue & $74(100)$ & $37(100)$ & $37(100)$ & NA \\
\hline Orthopnea & $70(94.6)$ & $36(97.3)$ & 34 (91.9) & 0.3 \\
\hline \multicolumn{5}{|l|}{ Physical findings } \\
\hline Systolic BP, mean (SD), mmHg & $142.7(36)$ & $146.8(39.7)$ & $138.6(31.8)$ & 0.3 \\
\hline Diastolic BP, mean (SD),mmHg & $94.2(28.5)$ & $97.7(34.4)$ & $90.8(20.8)$ & 0.2 \\
\hline Mean $\mathrm{BP}$, mean (SD), mmHg & $110.4(29.6)$ & $114.1(34.7)$ & $106.7(23.4)$ & 0.4 \\
\hline Heart Rate, mean (SD), bpm & $96.5(20.2)$ & $94.3(24.6)$ & $98.6(14.5)$ & 0.02 \\
\hline Pedaledema, n(\%) & $66(89.2)$ & 35 (94.6) & $31(83.8)$ & 0.2 \\
\hline Rales, n (\%) & $58(78.4)$ & $30(81.1)$ & $28(75.7)$ & 0.6 \\
\hline \multicolumn{5}{|l|}{ Etiologies of Heart Failure } \\
\hline Rheumatic Heart Disease & $5(6.8)$ & $3(8.1)$ & $2(5.4)$ & 0.6 \\
\hline Hypertensive Heart Disease & $36(48.7)$ & $22(59.5)$ & $14(37.8)$ & 0.06 \\
\hline Idiopathic dilatedCardiomyopathy & $7(9.5)$ & $5(13.5)$ & $2(5.4)$ & 0.2 \\
\hline Ischemic Heart Disease & $8(10.8)$ & $1(2.7)$ & $7(18.9)$ & 0.03 \\
\hline HIV Heart Disease & $1(1.4)$ & 0 & $1(2.7)$ & NA \\
\hline Cor Pulmonale & $8(10.8)$ & $2(5.4)$ & $6(16.2)$ & 0.13 \\
\hline Peripartum Cardiomyopathy & $1(1.4)$ & $1(2.7)$ & 0 & NA \\
\hline Others & $8(10.8)$ & $3(8.1)$ & $5(13.5)$ & 0.46 \\
\hline
\end{tabular}

BP Blood Pressure; eGFR estimated Glomerular Filtration Rate; NA non-applicable, NYHA New York Heart Association; SD Standard Deviation 
CI: 9.7-28.2]) patients. These patients with known HF were all on diuretics (non-anti-aldosterone), eight on angiotensin-converting enzyme inhibitors, five on betablockers, and six on spironolactone. Five patients $(6.8 \%$, [95\% CI: 2.2-15.1]) had a history of CKD. The echocardiographic and biochemical characteristics are shown in Table 2. Left atrial dilatation was the most frequent echocardiographic finding, seen in 58 (78.1\%, [95\% CI: 67.3-87.1]) patients. Biventricular heart failure was the most frequent type, seen in $42(56.8 \%$, [95\% CI:
44.7-68.2]) patients. Hypertensive heart failure was the most frequent etiology of HF.

\section{Frequency of kidney dysfunction}

The eGFR ranged between 4.2 and $161.2 \mathrm{ml} / \mathrm{min} / 1.73 \mathrm{~m} 2$, with a median of 60.3 (IQR44-88.9). There was no statistically significant difference in eGFR between males (64.5 [SD 33.7]) and females (72.8 [SD 40.0]), $p=0.614$. Any kidney dysfunction (eGFR $<90 \mathrm{ml} / \mathrm{min} / 1.73 \mathrm{~m}^{2}$ ) was seen in 56 (75.7\%, [95\% CI: 64.3-84.9]) patients.

Table 2 Echocardiographic and biochemical characteristics in patients hospitalized with heart failure $(n=74)$ : overall and by categories of kidney function

\begin{tabular}{|c|c|c|c|c|}
\hline \multirow[t]{2}{*}{ Variable } & \multirow[t]{2}{*}{ Overall $(n=74)$} & \multicolumn{2}{|c|}{ eGFR $\left(\mathrm{ml} / \mathrm{min} / 1.73 \mathrm{~m}^{2}\right)$} & \multirow[t]{2}{*}{$p$-value } \\
\hline & & $<60(n=37)$ & $\geq 60(n=37)$ & \\
\hline \multicolumn{5}{|l|}{ Mean (SD) values } \\
\hline Septum (mm) & $10.3(2.8)$ & $10.9(3.1)$ & $9.8(2.4)$ & 0.12 \\
\hline Posterior wall (mm) & $10.4(2.7)$ & $10.9(3.2)$ & $9.8(1.9)$ & $<0.01$ \\
\hline LV End-diastolic diameter (mm) & $57.8(11)$ & $59.5(8.9)$ & $48.8(11.8)$ & 0.03 \\
\hline LV End-systolic diameter (mm) & $46.7(13.4)$ & $48.8(11.8)$ & $44.5(14.7)$ & 0.1 \\
\hline Relative Wall Thickness & $0.38(0.2)$ & $0.38(0.13)$ & $0.38(0.17)$ & 0.4 \\
\hline LV Mass (g) & $249.4(101.4)$ & $278.8(111)$ & $219(81.4)$ & 0.1 \\
\hline LV Ejection fraction (\%) & $38.7(19.6)$ & $37.2(16.1)$ & $40.2(22.7)$ & $<0.01$ \\
\hline LV Fractional shortening (\%) & $19.7(11.9)$ & $18.4(9.8)$ & $21.1(13.7)$ & 0.01 \\
\hline LA area $\left(\mathrm{cm}^{2}\right)$ & $24.7(6.9)$ & $25.4(5.9)$ & $24(7.7)$ & 0.2 \\
\hline LA Diameter (mm) & $41.6(8.4)$ & $43.2(8)$ & $40.1(8.7)$ & 0.5 \\
\hline RA Area $\left(\mathrm{cm}^{2}\right)$ & $20.7(6.9)$ & $20.3(6.1)$ & $21.1(7.7)$ & 0.5 \\
\hline TAPSE (mm) & $15.3(2.3)$ & $15.5(2.4)$ & $15(2.2)$ & 0.7 \\
\hline E-wave Deceleration time (ms) & $118.2(36.1)$ & $120.6(35.3)$ & $115.9(37.2)$ & 0.7 \\
\hline E/A ratio & $1.88(0.95)$ & $1.82(0.8)$ & $1.93(1.04)$ & 0.6 \\
\hline PASP $(m m H g)$ & $63.7(20.5)$ & $62.1(19)$ & $65.6(22.3)$ & 0.3 \\
\hline Hemoglobin (g/dL) & $12.3(2.4)$ & $11.97(2.2)$ & $12.7(2.6)$ & 0.5 \\
\hline Creatinine (mg/L) & $18.4(20.5)$ & $26.6(26.4)$ & $10.1(3.9)$ & $<0.01$ \\
\hline $\operatorname{eGFR}\left(\mathrm{ml} / \mathrm{min} / 1.73 \mathrm{~m}^{2}\right)$ & $68.98(20.5)$ & $39.99(15.9)$ & $97.99(28.8)$ & $<0.01$ \\
\hline Natriemia (mmol/L) & $138.8(8.3)$ & $138.5(9.1)$ & $139.1(7.3)$ & 0.8 \\
\hline Kaliemia (mmol/L) & $3.9(0.8)$ & $3.96(0.8)$ & $3.86(0.8)$ & 0.7 \\
\hline Glycemia (g/L) & $1.22(0.6)$ & $1.16(0.4)$ & $1.29(0.8)$ & 0.05 \\
\hline \multicolumn{5}{|l|}{ Proportion, $n(\%)$ values } \\
\hline LV hypertrophy & $53(71.6)$ & $31(83.8)$ & $22(59.6)$ & 0.02 \\
\hline LA dilation & $58(78.4)$ & $31(86.5)$ & $26(70.3)$ & 0.1 \\
\hline RA dilation & $33(44.6)$ & $21(56.8)$ & $19(51.4)$ & 0.6 \\
\hline \multicolumn{5}{|l|}{ Type of HF syndrome } \\
\hline Isolated left Ventricular Failure & $22(29.7)$ & $13(35.1)$ & $9(24.3)$ & 0.3 \\
\hline Isolated right Ventricular Failure & $10(13.5)$ & $3(8.1)$ & $7(18.1)$ & \\
\hline Bi-ventricular Failure & $42(56.8)$ & $21(56.8)$ & $21(56.8)$ & \\
\hline LV Ejection Fraction < 40\% & $43(58.1)$ & $23(62.2)$ & $20(54.1)$ & 0.5 \\
\hline TAPSE $<17 \mathrm{~mm}$ & $52(70.3)$ & $24(64.9)$ & $28(75.7)$ & 0.3 \\
\hline $\mathrm{PASP}>35 \mathrm{mmHg}$ & $53(71.6)$ & $27(73)$ & $26(70.3)$ & 0.8 \\
\hline Anemia & $29(39.2)$ & $17(45.9)$ & $12(32.4)$ & 0.2 \\
\hline
\end{tabular}


Moderate-to-severe kidney dysfunction (eGFR $<60 \mathrm{ml} /$ $\mathrm{min} / 1.73 \mathrm{~m}^{2}$ ) was seen in 37 (50\%, [95\% CI: 38.1-61.9]) patients. Most of the patients with HF had mild kidney dysfunction (Fig. 1). All cases of kidney dysfunction were seen in those with left ventricular failure. Patients with a history of HF were more likely to have kidney impairment (Table 1). Those with kidney impairment significantly had lower heart rates, lower ejection fraction, and left ventricular hypertrophy (Tables 2 and 3). After adjusting for age $>55$ years, a history of chronic heart failure and increased LV mass parameters on echocardiography was associated with moderate to severe kidney impairment (Table 3).

\section{Outcomes}

Patients spent between 3 and 21 days in the hospital, with a median of 7.5 (IQR 6-11) days. Thirty-six (48.9\%, [95\% CI: 36.9-60.6]) patients had prolonged hospital stay ( $>7$ days). Kidney dysfunction was not significantly associated with prolonged hospital stay after adjusting for sex and age (adjusted odds ratio [aOR] 2.04, 95\% CI: 0.8-5.3).

In-hospital death occurred in seven $(9.5 \%$, [95\% CI: 3.5-18.5]) patients, including two with hyper-filtration, three with mild kidney dysfunction, and two with moderate kidney dysfunction. No patient with severe kidney dysfunction or those with normal kidney function died. Kidney dysfunction was not associated with in-hospital death (aOR 0.4, 95\% CI: 0.1-2). Those with kidney hyperfiltration (compared with those without) had a 4-fold higher in-hospital death (25\% versus $7.6 \%$; OR: $4.1,95 \%$ CI: 0.7-25.7]). This 4-fold higher odds for in-hospital death persisted after adjusting for sex and age (aOR 4.3, 95\%CI: 0.63-23).

\section{Sensitivity analysis}

After re-calculating the eGFR and excluding racial consideration, the median eGFR was 46.8 (IQR: 35-73.3) $\mathrm{ml} / \mathrm{min} / 1.73 \mathrm{~m}^{2}$. This was significantly lower than when the race was considered (mean difference of $12.7 \mathrm{ml} /$ $\left.\min / 1.73 \mathrm{~m}^{2}, p<0.001\right)$. The number of patients with an eGFR < 60 was 45 (60.8\%, [95\% CI: 48.8-72]) thus, a re-classification of $8(10.8 \%)$ patients to lower eGFR class (Kappa: 0.784, p <0.001). The eGFR was normal in $12(16.2 \%)$, mildly reduced in $16(21.6 \%)$, moderately reduced in $35(47.3 \%)$, severely reduced in $4(5.4 \%)$, and failure in 6 (8.1\%). Hyper-filtration was seen in 1 (1.4\%) patient. Factors associated with kidney dysfunction (Table S1) were; anemia (aOR: 3.0, $p=0.036$ ), chronic heart failure (aOR: 4.7, $p=0.052$ ), heart rate at admission $<90 \mathrm{bpm}$ (aOR: 3.4, $p=0.032$ ), left atrial dilation (aOR: 3.2, $p=0.034$ ), and hypertensive heart disease (aOR: 3.1, $p=0.021)$. Kidney dysfunction in HF was associated with hospital stay $>7$ days (OR: 2.6, [95\% CI: $1-6.8$ ], $p=0.050$ ) and not with in-hospital death (OR: 0.9, [95\% CI: 0.2$4.1], p=1.00)$.

\section{Discussion}

This study aimed to investigate the frequency, associated factors, and outcomes of kidney dysfunction in patients hospitalized for HF in a semi-urban setting in Cameroon. We found that moderate-to-severe kidney dysfunction (assessed with the MDRD equation considering black race) was seen in half of the patients hospitalized with HF and this was associated with a previous diagnosis of HF and left ventricular hypertrophy. In the sensitivity analysis (excluding racial consideration), kidney dysfunction was seen in over $60 \%$ of patients admitted with HF and this was associated with anemia, left atrial dilatation, and

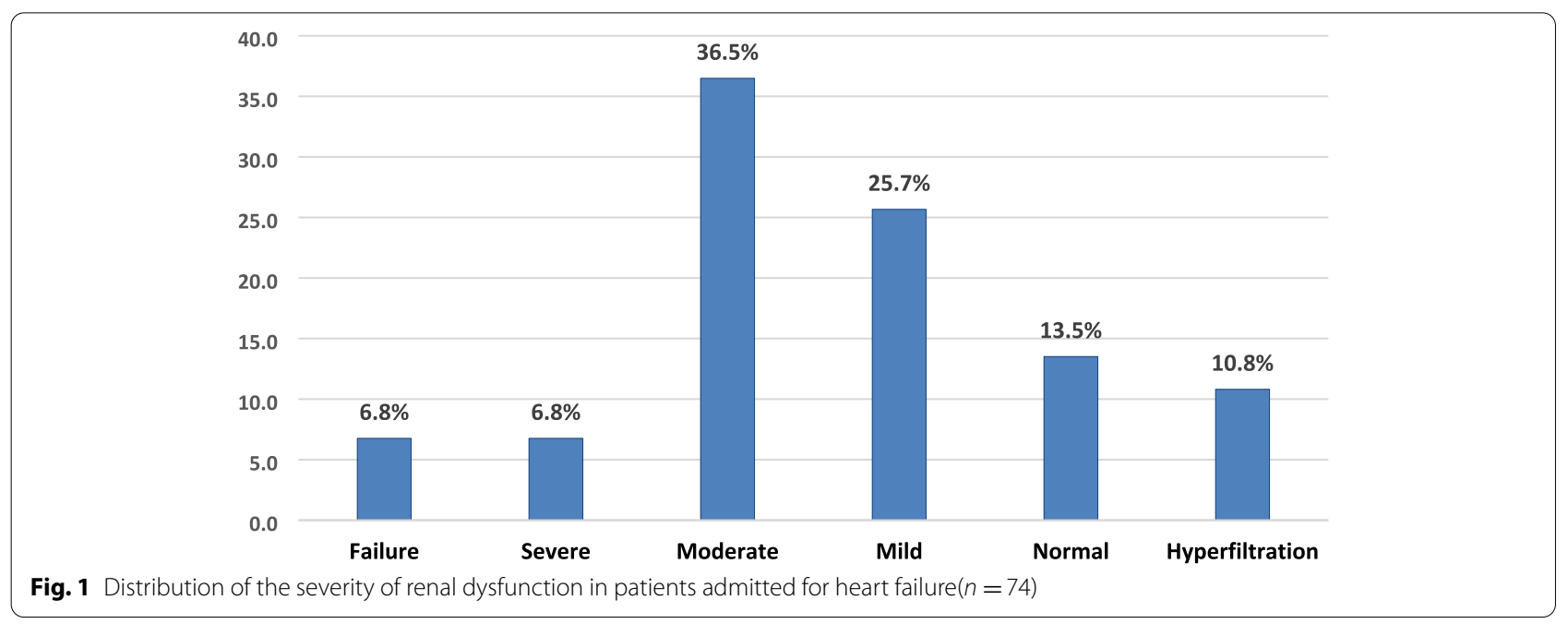


Table 3 Factors associated with an eGFR <60 ml/ $\min / 1.73 m^{2}(n=37)$ in patients hospitalized with heart failure $(n=74)$ (bivariate analyses and adjusting for age $>55$ years)

\begin{tabular}{|c|c|c|c|c|c|}
\hline \multirow[t]{2}{*}{ Variable } & \multirow[t]{2}{*}{ N (\%) } & \multicolumn{2}{|l|}{ Unadjusted } & \multicolumn{2}{|l|}{ Adjusted } \\
\hline & & OR $(95 \% \mathrm{Cl})$ & $p$-value & aOR $(95 \% \mathrm{Cl})$ & $p$-value \\
\hline
\end{tabular}

\section{Clinical data}

Age $>55$ years

$\begin{array}{lllll}\text { Yes } & 25(52.1) & 1.3(0.5-3.3) & 0.6 & \text { NA } \\ \text { No } & 12(46.2) & 1 & & \\ \text { History of Diabetes mellitus } & & \\ \text { Yes } & 5(45.5) & 0.8(0.2-2.9) & 0.7 & \text { NA } \\ \text { No } & 32(50.8) & 1 & & \end{array}$

History of Hypertension

\begin{tabular}{|c|c|c|c|c|c|}
\hline Yes & $22(52.4)$ & $1.3(0.5-3.1)$ & 0.6 & NA & \\
\hline No & $15(46.9)$ & 1 & & & \\
\hline \multicolumn{6}{|c|}{ Smoking } \\
\hline Yes & $4(66.7)$ & $2.1(0.4-12.4)$ & 0.7 & NA & \\
\hline No & $33(48.5)$ & 1 & & & \\
\hline \multicolumn{6}{|c|}{ Alcohol } \\
\hline Yes & $5(55.6)$ & $1.3(0.3-5.2)$ & 0.7 & NA & \\
\hline No & $32(49.2)$ & 1 & & & \\
\hline \multicolumn{6}{|c|}{ Anemia } \\
\hline Yes & $17(58.6)$ & $1.8(0.7-4.6)$ & 0.2 & $1.76(0.7-4.6)$ & 0.4 \\
\hline No & $20(44.4)$ & 1 & & 1 & \\
\hline \multicolumn{6}{|c|}{ Chronic Heart Failure } \\
\hline Yes & $10(76.9)$ & $4.2(1.1-16.8)$ & 0.03 & $4.3(1.1-17.5)$ & 0.03 \\
\hline No & $27(44.3)$ & 1 & & 1 & \\
\hline \multicolumn{6}{|c|}{ NYHA class 4} \\
\hline Yes & $13(41.9)$ & $0.6(0.2-1.5)$ & 0.2 & $0.6(0.2-1.5)$ & 0.3 \\
\hline No & $24(55.8)$ & 1 & & 1 & \\
\hline \multicolumn{6}{|c|}{ Heart rate $>90 / \mathrm{min}$} \\
\hline Yes & $19(40.4)$ & $0.3(0.160 .9)$ & 0.03 & $0.4(0.1-0.9)$ & 0.04 \\
\hline No & $18(66.7)$ & 1 & & 1 & \\
\hline \multicolumn{6}{|c|}{ Mean $\mathrm{BP}<80 \mathrm{mmHg}$} \\
\hline Yes & $4(66.7)$ & $2.1(0.4-12.4)$ & 0.7 & NA & \\
\hline No & $33(48.5)$ & 1 & & & \\
\hline \multicolumn{6}{|c|}{ Pedal edema } \\
\hline Yes & $35(53)$ & $3.4(0.6-18)$ & 0.3 & $3.3(0.6-17.5)$ & 0.3 \\
\hline No & $2(25)$ & 1 & & 1 & \\
\hline \multicolumn{6}{|l|}{ Rales } \\
\hline Yes & $30(51.7)$ & $1.4(0.5-4.2)$ & 0.8 & NA & \\
\hline No & $7(43.8)$ & 1 & & & \\
\hline \multicolumn{6}{|c|}{ Echocardiography } \\
\hline \multicolumn{6}{|c|}{ Left Ventricular Hypertrophy } \\
\hline Yes & $31(58.5)$ & $3.5(1.2-10.5)$ & 0.02 & $3.4(1.1-9.9)$ & 0.02 \\
\hline No & $6(28.6)$ & 1 & & 1 & \\
\hline \multicolumn{6}{|c|}{ LVEF $<40 \%$} \\
\hline Yes & $23(53.5)$ & $1.4(0.6-3.2)$ & 0.5 & NA & \\
\hline No & $14(45.2)$ & 1 & & & \\
\hline \multicolumn{6}{|c|}{ Left Atrial Dilation } \\
\hline Yes & $32(55.2)$ & $2.7(0.8-8.8)$ & 0.1 & $2.6(0.8-8.1)$ & 0.1 \\
\hline
\end{tabular}

Table 3 (continued)

\begin{tabular}{|c|c|c|c|c|c|}
\hline \multirow[t]{2}{*}{ Variable } & \multirow[t]{2}{*}{ N (\%) } & \multicolumn{2}{|l|}{ Unadjusted } & \multicolumn{2}{|l|}{ Adjusted } \\
\hline & & OR $(95 \% \mathrm{Cl})$ & $p$-value & aOR $(95 \% C l)$ & $p$-value \\
\hline No & $5(31.3)$ & 1 & & 1 & \\
\hline \multicolumn{6}{|c|}{ Left Heart failure } \\
\hline Yes & $34(52.3)$ & $2.2(0.5-9.5)$ & 0.5 & NA & \\
\hline No & $3(33.3)$ & 1 & & & \\
\hline \multicolumn{6}{|c|}{ Etiology of Heart Failure } \\
\hline \multicolumn{6}{|c|}{ Hypertensive Heart Disease } \\
\hline Yes & $22(61.1)$ & $2.4(0.95-6.1)$ & 0.06 & $2.35(0.92-6)$ & 0.07 \\
\hline No & 15 (39.5) & 1 & & 1 & \\
\hline \multicolumn{6}{|c|}{ Ischemic Heart Disease } \\
\hline Yes & $1(12.5)$ & $0.12(0.01-1.02)$ & 0.03 & $0.1(0.01-0.9)$ & 0.02 \\
\hline No & $36(54.6)$ & 1 & & 1 & \\
\hline \multicolumn{6}{|c|}{ Dilated Cardiomyopathy } \\
\hline Yes & $5(71.4)$ & $2.7(0.5-15.1)$ & 0.2 & NA & \\
\hline No & $32(47.8)$ & 1 & & & \\
\hline \multicolumn{6}{|c|}{ Cor pulmonale } \\
\hline Yes & $2(25)$ & $0.3(0.1-1.6)$ & 0.1 & NA & \\
\hline No & $35(53)$ & 1 & & & \\
\hline \multicolumn{6}{|c|}{ Rheumatic Heart Disease } \\
\hline Yes & $3(60)$ & $1.5(0.2-9.8)$ & 0.6 & NA & \\
\hline No & $34(49.3)$ & 1 & & & \\
\hline
\end{tabular}

aOR adjusted Odds Ratio, BP blood Pressure, $C l$ Confidence Interval, $L V E F$ Left Ventricular Ejection Fraction, NA Not computed, NYHA New York Heart Association

hypertensive heart disease. Kidney dysfunction might not be associated with in-hospital death but with prolonged hospital stay $>7$ days.

Data on the prevalence and correlates of kidney dysfunction in patients with HF in Cameroon are scarce [3]. The prevalence of kidney dysfunction in this study was significantly higher than that reported by other authors. In The Sub-Saharan Africa Survey of Heart Failure (THESUS-HF), 30.6\% of patients admitted with acute HF had kidney dysfunction [15]. In a multicenter study of patients with HF in SSA, Sani et al. reported a prevalence of $30.6 \%$ of kidney dysfunction on admission despite comparable aetiologies of HF with our study (predominant hypertensive heart disease). This could be due to the older age of our patients (60 vs 52 years), as kidney function declines with age [11]. In the CHARM study, Hillege et al. reported a prevalence of $36 \%$ in an older population of patients with HF with predominantly ischemic heart disease [14]. In a metaanalysis involving over 80 thousand patients, moderateto-severe kidney impairment was reported in $29 \%$ of patients with HF [16]. In a group of patients in Cameroon with hypertension and an average age of 60 years, Kaze et al. [12] reported a similar prevalence of about 
$50 \%$. In another group of patients with hypertension in Cameroon and an average age of 52 years, Hamadou et al. [20] reported a prevalence of $33 \%$, similar to that reported by Sani et al. [15]. This suggests that in SSA patients (similar age) with high rates of hypertension and kidney dysfunction, the occurrence of HF did not increase the rate of kidney dysfunction.

Factors traditionally associated with CKD in the general population are age, hypertension, diabetes, and obesity [11, 20, 21]. However, the determinants of kidney dysfunction in this small cohort were a history of HF and left ventricular hypertrophy. Those with kidney dysfunction also had statistically non-significant higher odd of the classic risk factors for CKD, with 2 fold odds associated with hypertension and smoking, and 1.6 fold odds associated with age. The relatively small sample did not permit us to detect statistically significant associations. The excess risk of kidney dysfunction in those with a history of HF could be explained by the treatment of HF- the use of diuretics and Angiotensin Converting Enzyme inhibitors or Angiotensin Receptor Blockers. Left ventricular hypertrophy is highly prevalent in patients with CKD, where it constitutes an independent risk factor for arrhythmias, sudden death, and progression of HF [22].

Kidney dysfunction is associated with excess mid- tolong-term mortality in patients with HF [16]. In this study, kidney dysfunction was not associated with inhospital death. We did not capture follow-up data after discharge. We found high but not significant odds of inhospital death in patients with HF and renal hyperfiltration. Renal hyperfiltration is associated with increased all-cause mortality in the general population, patients with diabetes, and those with atherosclerotic vascular disease [23-25]. The possible association between renal hyperfiltration and in-hospital death could be due to inherent adverse kidney disorder or marker of sarcopenia-associated with poor outcome in HF.

This study has some limitations. The accuracy of our estimates is limited by the relatively small sample size of the study, as shown by wide confidence intervals. The low number of patients in regression analyses might have precluded the detection of some significant associations. Furthermore, we did not collect data on proteinuria, an important marker of kidney dysfunction. In the absence of available kidney function before the index admission, it was not possible to differentiate CKD from acute kidney injury. Also, it was not possible to tell if the patients with high eGFR were true cases of glomerular hyperfiltration or due to sarcopenia with resultant low serum creatinine levels. There was no follow-up data to assess for medium and long-term outcomes. Despite these limitations, to the best of our knowledge, this study is the first to investigate the epidemiology of kidney dysfunction in patients with HF in a non-urban setting in Cameroon.

\section{Conclusion}

Moderate-to-severe kidney dysfunction (assessed with the MDRD equation and considering the black race) was seen in half of the patients hospitalized with HF in this setting, and this was associated with a previous diagnosis of heart failure and left ventricular hypertrophy on echocardiography. Kidney dysfunction was not associated with in-hospital death or hospital stay $>7$ days with the index hospitalization. We also found that patients with high eGFR were more likely to die during admission. Excluding racial consideration in the estimate (sensitivity analysis), mild-to-moderate kidney dysfunction was seen in $60 \%$ of patients admitted with $\mathrm{HF}$, and this was associated with anemia, chronic heart failure, heart rate at admission less than $90 \mathrm{bpm}$, left atrial dilatation, and hypertensive heart disease. Kidney dysfunction was associated with hospital stay $>7$ days.

There is a need for further studies with a larger cohort of patients with appropriate follow-up to better characterize the association of renal dysfunction with heart failure outcome in our context.

\section{Supplementary Information}

The online version contains supplementary material available at https://doi. org/10.1186/s12882-021-02641-2.

Additional file 1.

Acknowledgments

We thank the patients for participating in this study and also the nurses and support staff for assisting with the care of the patients.

Authors' contributions

Conception and design: A.M.J, C.N. Data acquisition: C.N. Data analysis and interpretation: A.M.J, C.N. and J.J.N. Drafting of the manuscript: A.M.J, C.N. and J.J.N. Critical review: All authors.

Funding

The authors did not receive any funding for the study.

Availability of data and materials

The datasets used and/or analyzed during the current study are available from the corresponding author on reasonable request.

\section{Declarations}

Ethics approval and consent to participate

The study was approved by the Ethics committees of the Buea Regional Hospital. The study conformed to the Declaration of Helsinki and participants provided written informed consent before enrollment.

Consent for publication

Not applicable. 


\section{Competing interests}

The authors declared no potential conflicts of interest with respect to the research, authorship, and/or publication of this article.

\section{Author details}

${ }^{1}$ Faculty of Health Sciences, University of Bamenda, Bamenda, Cameroon. ${ }^{2}$ Buea Regional Hospital, Buea, Cameroon. ${ }^{3}$ Clinical Research Education, Networking and Consultancy (CRENC), Douala, Cameroon. ${ }^{4}$ Center for Heart Rhythm Disorders, University of Adelaide, Adelaide, SA, Australia. ${ }^{5}$ Faculty of Health Sciences, University of Buea, Buea, Cameroon. ${ }^{6}$ Faculty of Medicine and Biomedical Sciences, University of Yaounde 1, Yaoundé, Cameroon.

Received: 15 March 2021 Accepted: 17 December 2021

Published online: 03 January 2022

\section{References}

1. Yuyun MF, Sliwa K, Kengne AP, Mocumbi AO, Bukhman G. Cardiovascular Diseases in Sub-Saharan Africa Compared to High-Income Countries: An Epidemiological Perspective. Glob Heart. 2020;15(1):15.

2. Agbor VN, Essouma M, Ntusi NAB, Nyaga UF, Bigna JJ, Noubiap JJ. Heart failure in sub-Saharan Africa: A contemporaneous systematic review and meta-analysis. Int J Cardiol. 2018:257:207-15.

3. AbdElHafeez S, Bolignano D, D'Arrigo G, Dounousi E, Tripepi G, Zoccali C. Prevalence and burden of chronic kidney disease among the general population and high-risk groups in Africa: a systematic review. BMJ Open. 2018:8:1.

4. Kingue S, Dzudie A, Menanga A, Akono M, Ouankou M, Muna W. A new look at adult chronic heart failure in Africa in the age of the Doppler echocardiography: the experience of the medicine department at Yaounde General Hospital. Ann CardiolAngeiol (Paris). 2005;54(5):276-83.

5. Nkoke C, Jingi AM, Aminde LN, Teuwafeu D, Nkouanlack C, Noubiap JJ, et al. Heart failure in a semi-urban setting in Cameroon: clinical characteristics, etiologies, treatment, and outcome. Journal of Xiangya Medicine. 2019.

6. TantchouTchoumi JC, Ambassa JC, Kingue S, Giamberti A, Cirri S, Frigiola $A$, et al. Occurrence, aetiology and challenges in the management of congestive heart failure in sub-Saharan Africa: experience of the Cardiac Centre in Shisong, Cameroon. Pan Afr Med J. 2011.

7. Patrice HM, Pascal KA, François KF, Hilaire D, Solange DM, Gloria AE, et al. Markers and risk factors for chronic kidney disease in sub-Saharan Africans: baseline levels and 12-month trajectories in newly referred patients in Cameroon. BMC Nephrol. 2020;21(1):101.

8. KuateDefo B, Mbanya JC, Kingue S, Tardif J-C, Choukem SP, Perreault S, et al. Blood pressure and burden of hypertension in Cameroon, a microcosm of Africa: a systematic review and meta-analysis of populationbased studies. J Hypertens. 2019;37(11):2190-9.

9. Kingue S, Ngoe CN, Menanga AP, Jingi AM, Noubiap JJN, Fesuh B, et al. Prevalence and risk factors of hypertension in urban areas of Cameroon: a Nationwide population-based cross-sectional study. J Clin Hypertens. 2015;17(10):819-24.

10. Bigna JJ, Nansseu JR, Katte J-C, Noubiap JJ. Prevalence of prediabetes and diabetes mellitus among adults residing in Cameroon: a systematic review and meta-analysis. Diabetes Res ClinPract. 2018;137:109-18.

11. Aseneh JB, Kemah B-LA, Mabouna S, Njang ME, Ekane DSM, Agbor VN. Chronic kidney disease in Cameroon: a scoping review. BMC Nephrol. 23 Sept 2020.

12. Kaze FF, Kengne A-P, Magatsing CT, Halle M-P, Yiagnigni E, Ngu KB. Prevalence and determinants of chronic kidney disease among hypertensive Cameroonians according to three common estimators of the glomerular filtration rate. J ClinHypertens Greenwich Conn. 2016;18(5):408-14.

13. Schefold JC, Filippatos G, Hasenfuss G, Anker SD, von Haehling S. Heart failure and kidney dysfunction: epidemiology, mechanisms, and management. Nat Rev Nephrol. 2016;12(10):610-23.

14. Hillege HL, Nitsch D, Pfeffer MA, Swedberg K, McMurray JJV, Yusuf S, et al. Renal function as a predictor of outcome in a broad spectrum of patients with heart failure. Circulation. 2006;113(5):671-8.

15. Sani MU, Davison BA, Cotter G, Sliwa K, Edwards C, Liu L, et al. Renal dysfunction in African patients with acute heart failure. Eur J Heart Fail. 2014;16(7):718-28.
16. Smith GL, Lichtman JH, Bracken MB, Shlipak MG, Phillips CO, DiCapua P, et al. Renal impairment and outcomes in heart failure: systematic review and meta-analysis. J Am CollCardiol. 2006;47(10):198796.

17. Ponikowski P, Voors AA, Anker SD, Bueno H, Cleland JGF, Coats AJS, et al. ESC guidelines for the diagnosis and treatment of acute and chronic heart failure: the task force for the diagnosis and treatment of acute and chronic heart failure of the European Society of Cardiology (ESC) developed with the special contribution of the heart failure association (HFA) of the ESC. Eur Heart J. 2016;37(27):2129-200.

18. O'Meara E, Chong KS, Gardner RS, Jardine AG, Neilly JB, McDonagh TA. The modification of diet in renal disease (MDRD) equations provide valid estimations of glomerular filtration rates in patients with advanced heart failure. Eur J Heart Fail. Jan 2006;8(1):63-7.

19. Helal I, Fick-Brosnahan GM, Reed-Gitomer B, Schrier RW. Glomerular hyperfiltration: definitions, mechanisms, and clinical implications. Nat Rev Nephrol. 2012;8(5):293-300.

20. Hamadou B, Boombhi J, Kamdem F, Fitame A, Amougou SN, Mfeukeu LK, et al. Prevalence and correlates of chronic kidney disease in a group of patients with hypertension in the Savanah zone of Cameroon: a cross-sectional study in sub-Saharan Africa. CardiovascDiagnTher déc. 2017;7(6):581-8.

21. Kaze FF, Halle M-P, Mopa HT, Ashuntantang G, Fouda H, Ngogang J, et al. Prevalence and risk factors of chronic kidney disease in urban adult Cameroonians according to three common estimators of the glomerular filtration rate: a cross-sectional study. BMC Nephrol. 2015.

22. Giamouzis G, Kalogeropoulos AP, Butler J, Karayannis G, Georgiopoulou W, Skoularigis J, et al. Epidemiology and importance of renal dysfunction in heart failure patients. Curr Heart Fail Rep déc. 2013;10(4):411-20.

23. Park M, Yoon E, Lim Y-H, Kim H, Choi J, Yoon H-J. Renal hyperfiltration as a novel marker of all-cause mortality. J Am Soc Nephrol JASN juin. 2015;26(6):1426-33.

24. Penno G, Solini A, Bonora E, Orsi E, Fondelli C, Zerbini G, et al. Defining the contribution of chronic kidney disease to all-cause mortality in patients with type 2 diabetes: the renal insufficiency and cardiovascular events (RIACE) Italian multicenter study. ActaDiabetol. juin 2018;55(6):603-612.

25. Inrig JK, Gillespie BS, Patel UD, Briley LP, She L, Easton JD, et al. Risk for cardiovascular outcomes among subjects with atherosclerotic cardiovascular disease and greater-than-normal estimated glomerular filtration rate. Clin J Am SocNephrol CJASN. 2007;2(6):1215-22.

\section{Publisher's Note}

Springer Nature remains neutral with regard to jurisdictional claims in published maps and institutional affiliations.

Ready to submit your research? Choose BMC and benefit from

- fast, convenient online submission

- thorough peer review by experienced researchers in your field

- rapid publication on acceptance

- support for research data, including large and complex data types

- gold Open Access which fosters wider collaboration and increased citations

- maximum visibility for your research: over 100M website views per year

At BMC, research is always in progress.

Learn more biomedcentral.com/submissions 